\title{
Motorization and Under-Reported Road Accidents: Spatial Evidence from Pakistan
}

\author{
Farrukh Baig ${ }^{1}$, Sajan Shaikh², Mir Aftab Hussain Talpur ${ }^{3}$ \\ RECEIVED ON 04.03.2019, ACCEPTED ON 16.12.2020
}

\begin{abstract}
Considering the importance of road safety, as discussed in the agenda of World Health Organization-2030; this study folds motorization and under-reporting of road accidents in Punjab, Pakistan. The objectives of the study are selected as 1) identifying the motorization in Punjab; 2) synthesizing the vehicles dominance by preparing spatial maps on the basis of their types; 3) identifying the evidence of under-reporting of road accidents. Compound Annual Growth Rate (CAGR) of different vehicles were estimated, and spatial maps were generated using ArcGIS to demonstrate the spatial distribution of vehicles (CAGR). Results indicated the potential impact of geographical locations on the CAGR of vehicles. The CAGR of registered vehicles was recorded as: $2.73 \%$ to $\mathbf{9 . 9 3 \%}$ for Cars; $\mathbf{1 2 . 6 3 \%}$ to $18.94 \%$ for Motorcycles; $9.35 \%$ to $24.1 \%$ for Rickshaws; $0.74 \%$ to $7.29 \%$ for Trucks and $5.25 \%$ to $14.42 \%$ for Vans. On the other hand, the CAGR of road length varied from $0.35 \%$ to $12.03 \%$ that illustrated the alarming situation of increased motorization. Sluggish infrastructural development and the huge recorded difference in CAGR can be categorized as the possible causes of immense road accidents. By comparing reported road accidents with Punjab Emergency Service (PES) estimations; the average rate of annual under-reported road accidents was found as $62.6 \%$ that also showed variations, according to different administrative regions of the Punjab province. Study findings suggests that the development of effective transportation policy, focusing road safety may help Pakistan to curtail road accidents and induce free-flow of traffic.
\end{abstract}

Keywords: Compound Annual Growth Rate (CAGR), Vehicle Dominance, Road Accidents, Spatial Mapping, Safety, Mitigation Strategies.

\section{INTRODUCTION}

I mmense urbanization, as well as steady economic development have heightened the motorization growth [1]. The term motorization reflects the excess of vehicular ownership and usage [2]. The rapid motorization results in traffic safety issues besides the environmental pollution [3]. In Asian countries, where the developing economies are experiencing hasty population growth and lack of funds for transportation infrastructure development, motorization can be regarded as a major issue, as discussed by transport planners [4]. Increasing motorization trend together with improper traffic management system always results in fatal accidents, injuries, and damages to properties [5]. Statistically, road accidents caused 1.2 million deaths every year [6]. Road accidents are continuously increasing in developing countries, because of the high proportion of road users, lack of traffic management, inadequate transport infrastructure, and proper implementation traffic rules

\footnotetext{
${ }^{1}$ School of Traffic and Transportation Engineering, Central South University, Changsha, Hunan. 410075, P.R. China. Email: farrukhbaig@ mail.dlut.edu.cn (Corresponding Author).

${ }^{2}$ School of Transportation, Southeast University, Nanjing 211189, China. Email: shaikhsajan402@ gmail.com

${ }^{3}$ Department of City and Regional Planning, Mehran University of Engineering and Technology, Jamshoro, Sindh, Pakistan. Email: aftab.talpur@ faculty.muet.edu.pk
}

This is an open access article published by Mehran University of Engineering and Technology, Jamshoro under CC BY 4.0 International License. 
or regulations [7]. Motorization and road accidents both are inter-related and need appropriate attention in various countries, where rapid motorization caused severe road accidents $[3,8]$.

World Health Organization (WHO) included road safety parameter in 2030 agenda for sustainable development in order to tackle the increasing fatal road accidents $[9,10]$. Road fatalities have been widely discussed in literature in context of various countries [11-17]. Yet, little attention has been paid to record the evidence for under-reporting of road accidents, which definitely put a question mark on the allocation of road safety funds. Although, the main source of road accident data, which can be used for road safety and accident prevention, is police department or other public sector organizations; in spite of that underreporting of accidents is common in most of the third world countries [18]. In a country like Pakistan, where transportation policy never gets proper attention in the past, motorization phenomenon, as well as transportation safety issues, need more attention [19]. Recently, the Pakistan government drafted a national transport policy to improve the country's transportation sector, which also failed to address the issues of motorization management and underreported road accidents [20].

By considering the alarming road safety situation of developing countries specifically Pakistan [21]; this study attempts to highlight the current situation of motorization and its spatial distribution, coupled with under-reporting of road accidents in Punjab-Pakistan. The objectives of the study are selected as 1) identifying the motorization situation in Punjab; 2) explaining the vehicles dominancy with spatial maps on the basis of their types; 3 ) identifying the evidence of under-reporting of road accidents. Moreover, CAGR of various types of vehicles were estimated and presented spatially with the help of digitized maps, and suggestions were also proposed to mitigate the related issues of road transportation. In particular, this study is significant in the sense that it can help policymakers to understand the potential differences in growth of various types of vehicles in PunjabPakistan. Furthermore, this research also discusses under-reporting of road accidents, which may be a reason for embezzlers in allocated funds. In the end, it can be said that the present study may be utilized and referenced as a key document for the development of better road safety policy in Pakistan and related developing countries.

\section{LITERATURE REVIEW}

\subsection{Motorization and Road Accidents}

Amongst Asian countries, Pakistan is facing continuous increase in motorization since its independence [22-24]. Whilst, this tendency would likely to continue in future after successful completion of the China-Pakistan Economic Corridor (CPEC), which is a part of China's "one belt one road" project [25]. As a result, increased motorization would prevail, which may further exaggerate road accidents on outdated transport infrastructure without proper traffic management rules or regulations [3]. The road fatalities comparatively decreased in developed countries; however, in Pakistan, the road accident rate is mounting with the passage of time [26]. According to World Bank development indicators, Pakistan is categorized as lower-middle income country [27], where the absence of credential data is a serious issue, which could assist professionals to draw conclusions, as preventative measures could be taken for the future [26]. In the year 2013, the road fatalities in Pakistan were reported as 7,636; but, according to $\mathrm{WHO}$, the total estimated annual road fatalities were around 25,781 , which highlight the concern of underreporting [10]. Table 1 illustrated the number of reported road accidents collected via year wise provincial reports of Pakistan Bureau of Statistics (www.pbs.gov.pk/). It highlights the highest rate of road accidents in Punjab province. The variations in trend indicated the under reported accidents and data ascertainment situation pertinent in respective provinces. This severe under-reporting of road accidents can be an outcome of improper funds distribution for road safety that can be regarded as a hurdle in taking the preventive actions for road accidents. Besides, Punjab province was depicted to have a highest share of road accidents as compared to Sindh, Khyber Pakhtunkhuwa (KPK) and Balochistan provinces which highlights the severity of road accident issue. 
In developing countries including Pakistan, Police Department is considered as an only major source of road accident data, which can be one of the possible causes of under-reporting [17]. Simultaneously, the reliability of road accident statistics is also a serious issue in Pakistan, because of the under-reporting [13]. Batool et al. [28] thoroughly discussed road safety issues in Pakistan, and found five loop wholes: (a) institutional issues; (b) execution; (c) physical and operational problems; (d) altitudinal and behavior matters; (e) accident research and data bank research. In past, an independent transportation policy was a matter of serious concern in Pakistan. The Five Year Plans were developed to achieve development goals, including transportation sector [19]; nonetheless, recently, Government of Pakistan drafted a National Transportation Policy-2017 to manage the future investments and improvement in transport sector [20]. The National Transport Policy-2017 comprehensively focused the road safety issues, together with high motorization problems in general context; but, road accidents under-reporting and absence of road accidents data were not precisely discussed.

\subsection{Research deficiency in Pakistan related to motorization and road accidents}

For the better understandings, native and neighboring countries Scopus-indexed research articles of last twodecades were found useful on the subject matter, i.e. motorization and road accidents [29]. On 28 $8^{\text {th }}$ November 2018, key words, e.g. "motorization" and "road accidents," were searched on Scopus search engine, and a total number of available research articles in the database were counted. Country's affiliation was also specified to get the country-wise results. Likewise, the filter was also used on both search results; language was selected as "English," and the result was restricted to retrieve research articles from the years 1998 to 2018. In this way, twodecades publication data were obtained and presented in Fig. 1 to show country-wise statistics.

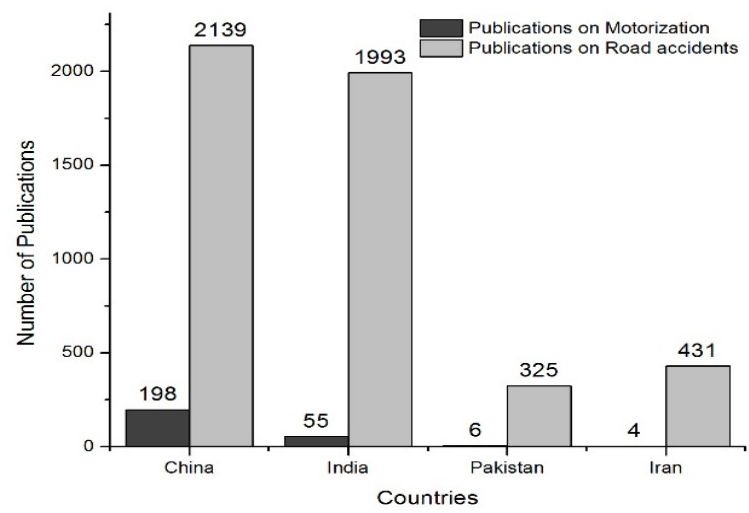

Fig. 1. Number of publications on motorization and road accidents, published in the last two decades

As shown in Fig.1, Pakistan exhibited the least number of research publications related to "road accidents," and few studies were conducted to explain "motorization". This situation indicates dire need to focus on these issues for research in the context of Pakistan. China leads as compared to its neighboring countries on the subject matter; whereas, India was found next to China with total 1993 publications related to road accidents and motorization.

\begin{tabular}{|c|c|c|c|c|}
\hline \multicolumn{5}{|c|}{ Table 1: Year wise distribution of reported road accidents } \\
\hline Year & $\begin{array}{c}\text { Reported road } \\
\text { accidents in Punjab } \\
\text { province }\end{array}$ & $\begin{array}{c}\text { Reported road } \\
\text { accidents in Sindh } \\
\text { province }\end{array}$ & $\begin{array}{c}\text { Reported road } \\
\text { accidents in KPK } \\
\text { province }\end{array}$ & $\begin{array}{c}\text { Reported road } \\
\text { accidents in } \\
\text { Balochistan province }\end{array}$ \\
\hline 2006 & 5355 & 1618 & 2942 & 551 \\
\hline 2007 & 5522 & 1561 & 2893 & 490 \\
\hline 2008 & 5240 & 1433 & 2392 & 431 \\
\hline 2009 & 5344 & 1465 & 2559 & 379 \\
\hline 2010 & 5420 & 1270 & 2722 & 311 \\
\hline 2011 & 4990 & 1054 & 2772 & 324 \\
\hline 2012 & 4587 & 935 & 2968 & 297 \\
\hline 2013 & 3696 & 945 & 3120 & 342 \\
\hline 2014 & 3054 & 881 & 3399 & 315 \\
\hline 2015 & 3288 & 924 & 4287 & 357 \\
\hline
\end{tabular}




\subsection{Case Studies}

Road accidents and a rapid increase in the number of motor vehicles are considered as the most important emerging issue throughout the world [30, 31]. A growing body of literature has investigated the road accidents and motorizations, but few authors discussed the under-reporting issues of road accidents. There is an unambiguous relationship between motorization and road accidents, which has been briefly discussed in an Indonesian study [3]. The researcher used descriptive analysis to explain fatalities and motorization, in order to propose the mechanism of attaining useful traffic data and information, which may help in policies making related to motorization reduction. Similarly, another study descriptively discussed motorization and mobility development in the context of China, and also illustrated the need of motorization issue in the context of transport policy for better future planning [1]. To deal with motorization, Singapore experience provided a model to tackle the current transportation situation in Asian developing countries. Han [4], deliberated Singapore transportation policy development and delivered an alternative approach to attain sustainable transportation development by allowing parallel growth in motorization and public transit. Bhatti and Salmi [18], claimed the highest fatality rate in Eastern Mediterranean Region including Pakistan and used WHO smart criteria for measuring under-reporting issue. This study examined the statistical data on road accidents and found that the estimated fatalities were only $60 \%$ of the whole in most of the countries. They also suggested that financial and technical assistance from the developed world can be helpful to resolve the under-reporting issue. Tahir et al., [32] discussed road accidents patterns and causes by using rescue services data. Tahir et al. [32] also claimed that data reporting statistics can be improved, if it will be collected by ambulance services appropriately, which may become helpful in predicting and preventing accidents in the future. Another study, noticed-under reporting up to $33 \%$ of total road accidents in Sri Lanka, by analyzing the community-based survey results regarding road traffic injuries [33]. Similarly, descriptive research was conducted in Bhutan to identify a high level of under-reporting road accidents in Police records
Meanwhile, this study acknowledged the nonavailability of data collection and surveillance system for road accidents [34]. Watson et al. [35] used multiple linked data sources to estimate the underreporting extent in Australia. Study results indicated the severe under-reporting of road accidents on the basis of gender, age, road user group, and regional location. A cross-sectional study conducted in Chandigarh-India compared hospital and police reported accidents records to find the severity of under-reporting, and suggested adoption of standardized reporting format for both police and hospitals to manage road accident data [36]. Qin et al. [37] used the geographical information system to map and compare the vehicle crashes patterns for a selected period in urban and rural areas. Qin et al. [37] further found a potential impact of geographical location with traffic crash pattern and suggested to incorporate the area location for injury prevention initiatives.

In-depth review of literature depicts methodologies to measure motorization and also under-reporting of road accidents with minor differences. Mostly, the studies adopted descriptive methodologies to highlight the issues of both motorization and under-reporting of road accidents. Furthermore, previous literature provides the evidence of under-reporting by taking cities as an example. However, this study is introducing Punjab-Pakistan for the first time as an example to measure motorization at the divisional level and also under-reporting of road accidents. In the meantime, the GIS-based spatial mapping of (CAAGR) for Cars, Motorcycles, Rickshaws, Trucks, Vans and other vehicles is included to depict the spatial differences in vehicular growth, which actually is an addition to previous studies.

\section{STUDY AREA DEMOGRAPHICS}

Most of the countries had classified their land area administratively based on size or population. Similarly, Pakistan also possessed the hierarchy of administrative arrangements from smallest to large, i.e., Union Council, Tehsil/Town, District/City District, Division, Province and Country [38]. Among all the four provinces of Pakistan; Punjab, Sindh, 
Balochistan and Khyber Pakhtunkhwa, the province Punjab with the highest population of 110.01 million inhabitants, was selected for the present study [39-48]. Punjab, alone constituted $52.95 \%$ of the Country's population, with an area of 205345 sq.km and geographical location of $31^{\circ} \mathrm{N}, 72^{\circ} \mathrm{E}$ on globe [48]. As shown in Fig. 2, the Punjab province with its nine sub-divisions: 1. Bahawalpur 2. Dera Ghazi Khan (D.G. Khan) 3. Faisalabad 4. Gujranwala 5. Lahore 6. Multan 7. Rawalpindi 8. Sahiwal and 9. Sargodha were mapped to illustrate the population distribution in the province.

Lahore division has the highest population among all divisions as described in Fig. 2. Gujranwala and Faisalabad come after Lahore with respect to population and lie in a range of 12.28 to 16.12 million people. Whereas, Rawalpindi, Multan, Bahawalpur, and D.G. Khan lie in population range of 8.19 million to 12.27 million people. Sargodha and Sahiwal divisions have the least population among all and lie in the least range of population distribution.

\section{METHODOLOGY}

This study was attempted to review the previous literature regarding motorization and road accidents, analyzed the present situation of motorization and road accidents under-reporting by considering the spatial variations, and provided mitigation approaches. This work replicated and extended the previous studies on motorization [3] and road accidents under-reporting $[11,12,29]$. Whilst this research utilized spatial mapping technique for spatial distribution of CAGR of vehicles and also discussed road accidents statistics spatially. Meanwhile, this study also considered multiple divisions of a Punjab Province instead of one specific city, and explained the result at a broader level to provide spatial understanding at a larger scale. The objectives of the study were selected as 1) identifying the motorization situation in Punjab; 2) explaining the vehicles dominancy with spatial maps on the basis of their types; 3) identifying the evidence of underreporting of road accidents.

In Pakistan, the major source of road safety data is Pakistan Bureau of Statistics or its provincial departments, i.e., Punjab Bureau of Statistics [26]. For the present study, most updated data were extracted for the year of 2008-2016 from the yearly published statistical book named as "Punjab Development Statistics (2009-2017)" [39-48]. Though, the basic sources of data were the Excise and Taxation Department for "registered number of vehicles," and the provincial police department for "road accidents". Compounded Annual Growth Rate (CAGR) of Cars, Motorcycles, Rickshaws, Trucks, Vans and other vehicles were calculated by applying statistical modeling. Furthermore, Punjab Emergency Service (PES) statistics (related to road accidents) was obtained from their official website, to explain the evidence of the under-reporting of road accidents data

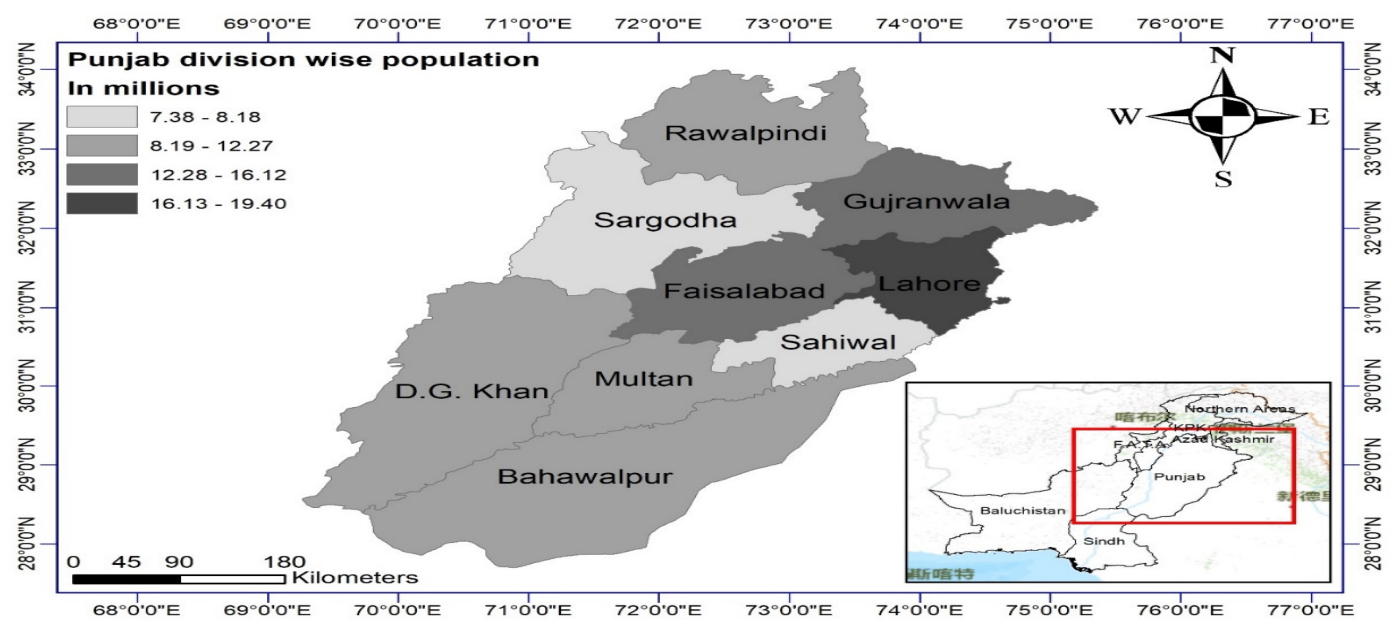

Fig. 2: Location Map of Punjab, Pakistan and Division Wise Population Distribution (As per Pakistan National Census 2017) 
[49]. Motorization level-based trends from the years 2008-2016 were made by origin lab. ArcGIS was also utilized to prepare maps and to clarify the spatial distribution of CAGR of vehicles. In the end, ArcGISbased maps were also developed to compare the recorded road accidents by Provincial Police Departments with PES. For preparing spatial maps, the first step was to obtain the Punjab based divisional boundaries from online sources such as open street maps etc. Secondly, obtained boundaries were matched with the actual ones. Thirdly, the manually input of collected data from grey literature was carried out. Finally, Symbology Quantities and Graduate Colors Technique were used to make shaded scale in ArcGIS. Spatial grouped of four different shaded scales, e.g. dominant, high, moderate and normal CAGR of vehicles were also developed. In this way, dominant risk areas and the issue of inaccuracy of spatial distribution of road accidents (due to underreported data) were illustrated with evidences. Recommendations and prevention strategies were also forwarded at the end in the light of literature review and findings.

\section{RESULTS AND DISCUSSION}

In order to measure annual motorization level for Punjab, we extracted the total number of registered vehicles and population from statistical reports 20082016. By using equation (1) [1], this study plotted motorization level for all nine divisions of Punjab, to check the trend and to provide guidelines for prioritizing the area wise policy actions.

\section{Motorization level $=$}

total number of registered $\frac{\text { vehicles }}{1000}$ persons

From 2008-2016, a continuous increasing trend of motorization was observed for all divisions of Punjab as illustrated in Fig. 3.

As explained in Fig. 3, the motorization level for every individual division was unique. Lahore division leads to the top and showed the highest motorization level since 2008-2016. In contrast, D.G. Khan exhibited the lowest motorization level for the same period of time. Among the rest of the divisions, Multan led with relatively higher motorization level. Faisalabad Bahawalpur, Rawalpindi, and Gujranwala lied close to each other in motorization level as compared to Sahiwal, which disclosed the slower increase in motorization level.

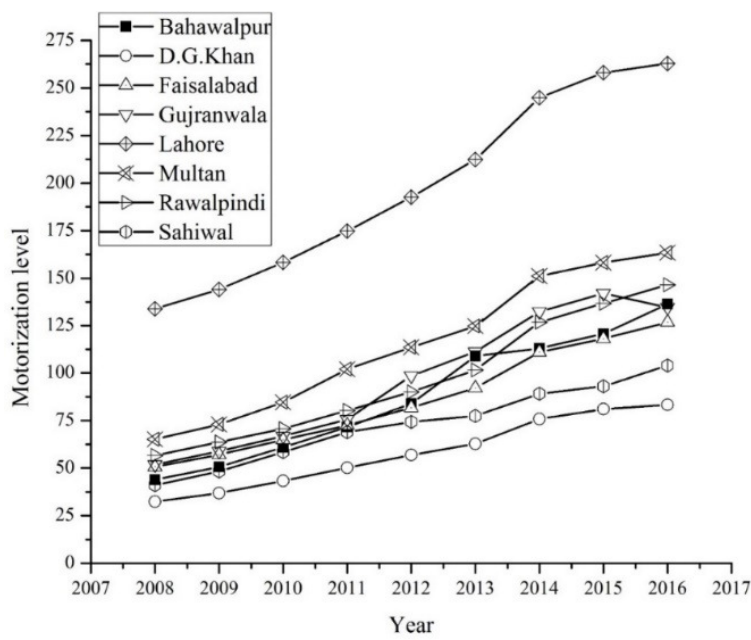

Fig. 3: Motorization Level of all divisions in Punjab

\subsection{Spatial Mapping of CAGR of Vehicles}

The general motorization level-based trend can only express the distribution of the whole number of registered motor vehicles over the specific period. In order to explain the dominancy of each vehicle type over the spatial area, CAGR for each type of vehicle and its spatial representation was considered as the best option. CAGR of Cars, Motorcycles, Rickshaws, Trucks, Vans and other vehicles which included (Taxis, Buses, Tractors and other types of motor vehicles) were taken into consideration for spatial maps. Similarly, the CAGR of roads (in kilometer) was also spatially mapped to know the relation of motorization with respect to roads. In spatial maps, four shaded ranges were formed to show "dominant, high, moderate and normal" levels of each vehicle growth rate. CAGR of road length increased with the range of $(0.35 \%$ to $12.03 \%)$ in last eight years in all Punjab divisions. CAGR of registered Cars varied from (2.73\% to 9.9\%); CAGR of Motorcycles varied from (12.63 to 18.94\%); CAGR of registered Rickshaws deviated from (9.35 to $24.1 \%$ ); CAGR of Trucks was (0.7 to $7.29 \%$ ), and CAGR of Vans was (5.25 to $14.42 \%$ ). CAGR of other vehicles recorded 
from (3.03 to 5.78\%) among all divisions of Punjab. In wider ranging, vehicle growth statistics showed the fastest growth in registered Motorcycles, as compared to the other types of vehicles, while the Trucks depicted lowest CAGR.

The CAGR variations of registered Cars at division level in Punjab demonstrated that Lahore, Multan and D.G Khan were dominant in terms of increasing number, having CAGR from 5.97 to $9.9 \%$ as a portrait in Fig. 4. While Bahawalpur was only at a high level and lied in range of $4.28 \%$ to $5.96 \%$, Rawalpindi and Sahiwal were at moderate levels $3.06 \%$ to $4.27 \%$; whereas, Faisalabad, Sargodha, and Gujranwala were considered relatively at normal levels with $(2.73 \%$ to $3.05 \%$ ). Comparatively, CAGR variation in registered Motorcycles were higher than Cars, which showed the increasing trend of Motorcycles in Punjab areas. Sargodha was dominant in the increasing rate of Motorcycles because it lied in the range of $(18.01 \%$ to $18.94 \%$ ) CAGR of registered Motorcycles. The number of registered Motorcycles increased in Rawalpindi, D.G. Khan, and Bahawalpur, as they lied in the range of $15.52 \%$ to $18 \%$ CAGR as shown in Fig. 5. CAGR of registered Motorcycles in Gujranwala, Faisalabad, Multan, and Sahiwal considered at moderate level, relatively with the range of $12.64 \%$ to $15.51 \%$ CAGR. Lahore was found only at normal level with $12.63 \%$ CAGR of registered Motorcycles. Results indicated a high increase in the number of Cars in Lahore, as compared to Motorcycles; whereas, the situation for Sargodha was vice versa.

The number of Rickshaws in all divisions was enhanced, as CAGR from 18.44 to $24.1 \%$ for the last eight years showed dominancy among other divisions (please, see Fig. 6). Rawalpindi, Gujranwala, and Sahiwal were at higher levels with the range of 11.8 to $18.43 \%$. Lahore, Bahawalpur, and Faisalabad were at a moderate level; hence, the range was 9.54 to $11.77 \%$. Multan and Sargodha were at a normal level, through their measurable scale varied from $9.35 \%$ to $9.53 \%$ CAGR. Lahore was only dominant in Trucks; its CAGR diverged from 2.7 to $7.29 \%$, which can be seen in Fig. 7. Multan and Bahawalpur were at a higher level with 1.57 to $2.69 \%$ CAGR. D.G. Khan, Rawalpindi and Gujranwala were at a moderate level, having $1.0 \%$ to $1.56 \%$ CAGR range. Sargodha and
Faisalabad were at a normal level with scale range from 0.74 to $0.99 \%$ CAGR.

CAGR of registered Vans can be depicted in Fig. 8. As shown, Rawalpindi, D.G Khan, Bahawalpur, and Multan were dominant among all divisions, and their CAGR percentages varied from 10.71 to $14.42 \%$. Gujranwala, Faisalabad, and Sahiwal were at a moderate level, having CAGR from 5.26 to $8.9 \%$. Only Sargodha was found at a normal level, having $5.25 \%$ CAGR value. The variable of other types of vehicles includes Buses, Tractors, Taxies, etc. CAGR of such type of vehicles is shown in Fig. 9. The percentage value range of Bahawalpur and Rawalpindi was considered dominant with the variation from 4.74 to $5.78 \%$ CAGR. Faisalabad and Multan were at a high level with range variation from $4.15 \%$ to $4.73 \%$ CAGR. Only Sahiwal lied at a normal level having $3.03 \%$ CAGR value; whereas, the remaining divisions were at a moderate level and their range was recorded as $3.04 \%$ to $4.14 \%$ CAGR.

Compounded Annual Growth Rate of road length is shown in Fig. 10. Lahore and Sargodha have higher growth rate, i.e., 1.04 to $12.03 \%$ CAGR. The figure also showed both divisions were dominant in increasing road length. Multan Gujranwala and Bahawalpur were at a high level by 0.87 to $1.03 \%$ CAGR. Gujranwala and D.G. Khan were at a moderate level by 0.46 to $0.86 \%$ CAGR. Rawalpindi, Faisalabad, and Sahiwal were at a normal level, having 0.35 to $0.45 \%$ CAGR.

Overall road length has a continuous increasing trend but Fig. 10 illustrated the CAGR of road length increase in order to provide evidence to compare it with vehicle dominancy based spatial maps presented in Fig. 4 to Fig. 9. It can be noticed that the CAGR of road length increase and registered vehicle increase in respective Punjab divisions were not found inline. The uneven increase in registered vehicle dominancy and road length development may lead the to increase the road accidents. This issue potentially stressed upon the need of efficient and reliable data management of vehicle dominancy and road accidents for the divisional boundaries. So that, effective road safety policy can be prepared with an ability to highlight the accident prone areas for an effective management of 


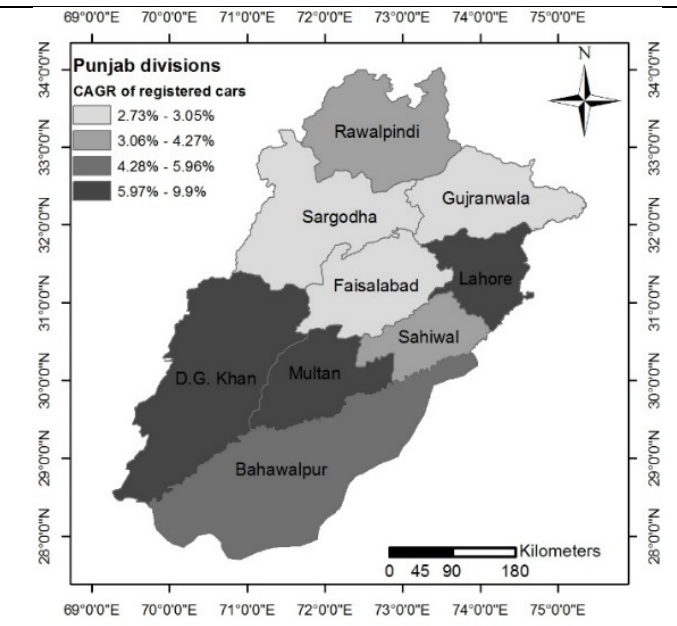

Fig. 4: Percentage Distribution of CAGR of registered cars

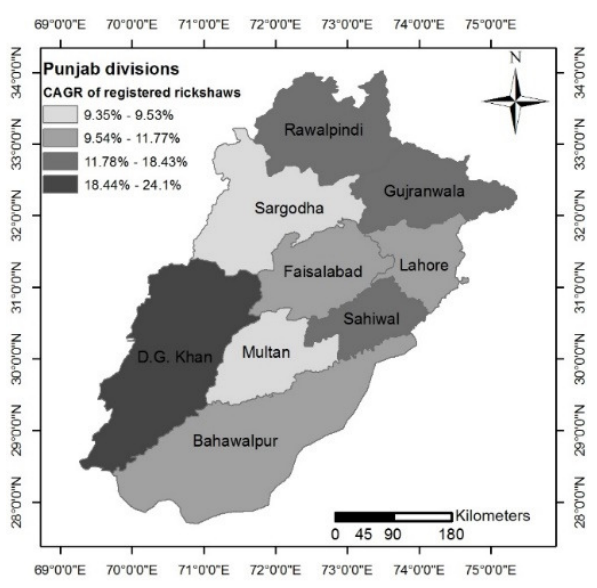

Fig. 6: Percentage Distribution of CAGR of Registered Rickshaws

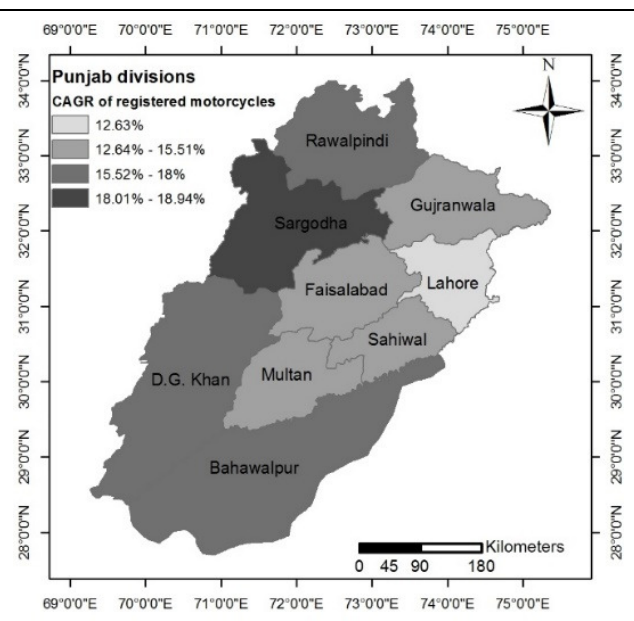

Fig. 5: Percentage distribution of CAGR of registered motorcycles

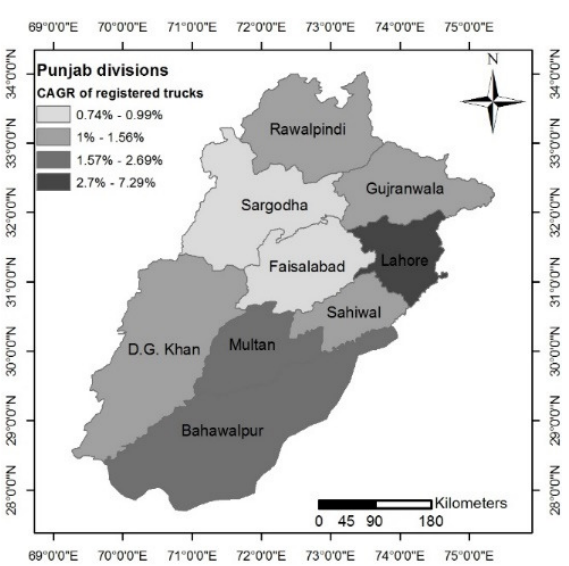

Fig. 7: Percentage Distribution of CAGR of Registered Trucks

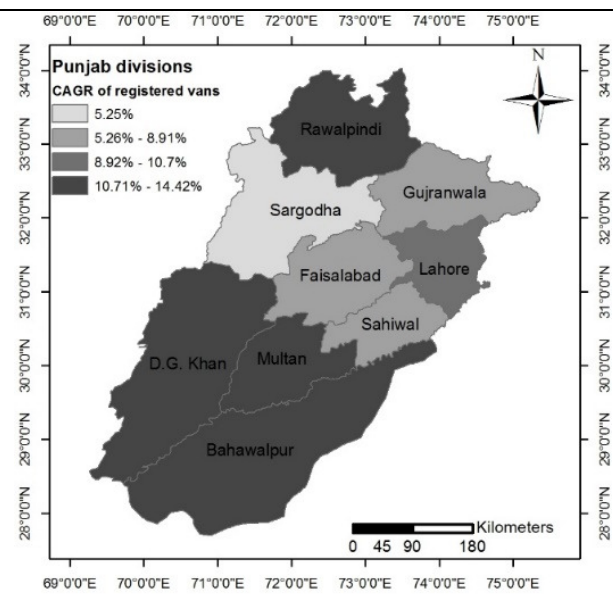

FIGURE 8. PERCENTAGE DISTRIBUTION OF CAGR OF REGISTERED VANS

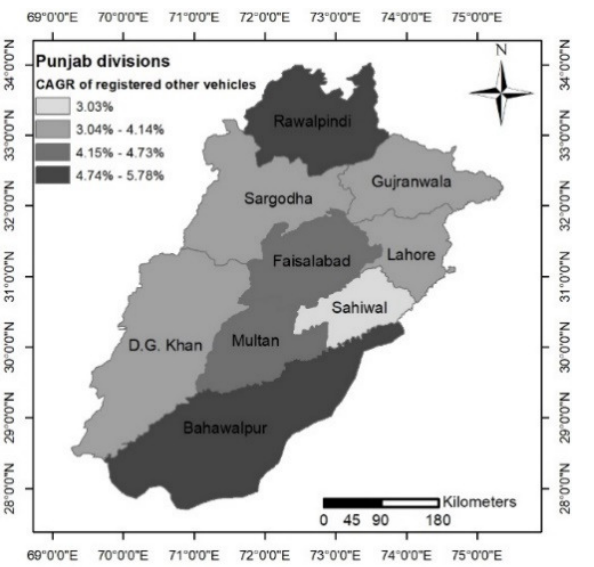

FIGURE 9. PERCENTAGE DISTRIBUTION OF CAGR OF REGISTERED OTHER VEHICLES 


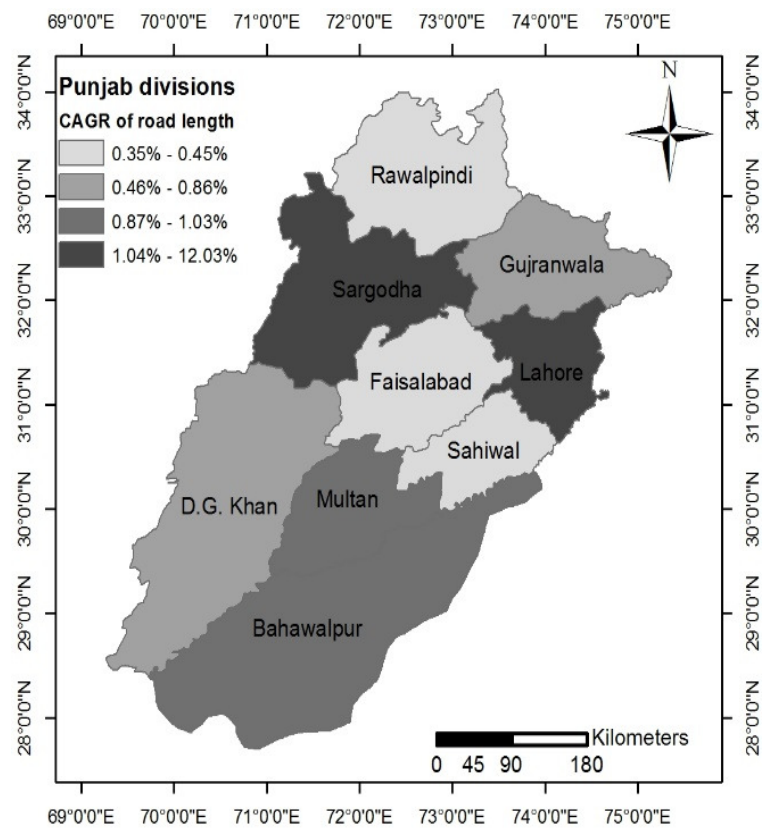

Fig. 10: Percentage Distribution of CAGR of Road Length Increase

future safety designs, transport development and resource allocation.

\subsection{Road Accidents in Punjab}

Reported road accidents statistics by Punjab Bureau of statistics (PBS) varied only from (0.27-1.16) in thousands, but the actual estimation by Punjab Emergency Services (PES) showed the presence of a large number of road accidents, having a range of (6.78-80.92) in thousands. This huge difference brings the study's attention towards the spatial distribution and comparison of average annual road accidents. There were the highest average annual road accidents (0.85 to 1.16 (in 1000)) reported in Lahore, and it was dominant in all divisions, as shown in Fig. 11. Gujranwala, Rawalpindi, D.G. Khan, and Bahawalpur were at high level with an annual average number from 0.48 to 0.84 (in 1,000). Sargodha and Faisalabad were at a moderate level with an annual average number from 0.37 to 0.47 (in 1,000). Multan and Sahiwal were at a normal level with an annual average number from 0.27 to 0.36 (in 1,000$)$.

Although, D.G. Khan was dominant in observed average annual accidents by PES data (See Fig. 12). Number of observed accidents lied from 43.38 to
80.92 (in 1,000). Lahore was at a higher level, having the values from 21.16 to 43.37 (in 1,000). Gujranwala, Faisalabad, and Multan were at a moderate level with the range from 10.39 to 21.15 (in1000). Rawalpindi Sargodha and Bahawalpur were at a normal level, i.e., from 6.78 to 10.38 (in1000). Furthermore, considering such deficiency in reported accidental data, as shown in Fig. 11 and Fig. 12, ultimately affects the fund's allocation in transportation planning sector, which caused lack of infrastructure management and increased road crashes. A comparison of average annual road accidents recorded from Punjab Emergency Services (PES) and reported to police provided in Table 2 emphasizing the issue of under reporting in all of the Punjab divisions.

Table 2 was aimed to indicate the percentage distribution of under-reporting road accidents of nine divisions of Punjab. Mostly, in Rawalpindi, having the range of $9.96 \%$; traffic accident data were underreported. However, in Sargodha, Bahawalpur, Gujranwala, Sahiwal, Lahore, Multan, Faisalabad, and D.G Khan; the under-reported data were noted as $6.86 \%, 6.64 \%, 3.13 \%, 3.08 \%, 2.31 \%, 1.94 \%$ and $0.8 \%$ respectively.

\section{CONCLUSION AND SUGGESTIONS}

\subsection{Research gap}

This study caters evidence of high motorization in Punjab based on spatial location, and also variations in under-reporting of road accidents among all divisions in Punjab. The findings of this study signified the need of spatial-based prioritization of economic, technical and policy-based resources to tackle the situation effectively. The evidence of motorization distribution of study area may help in policy preparation to manage the continuous increase of vehicles. At the same time, under-reporting of road accidents also highlighted with evidence, which showed the higher level of data mismanagement, and insufficient data recording system. By doing this, it was tried to brought the focus of policy makers to look towards the smart alternatives for data management so that data under reporting can be minimized to help in preparation of the mitigation 


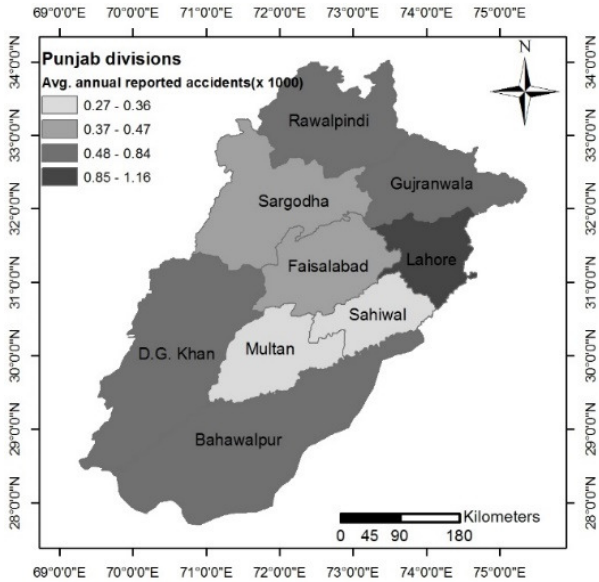

Fig. 11: Avg. Annual Road Accidents (Reported)

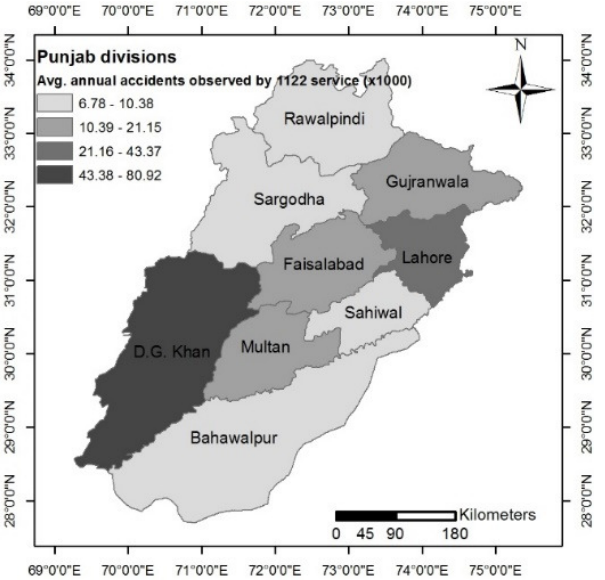

Fig.12: Avg. Annual Road Accidents (Estimated by PES)

\begin{tabular}{|c|c|c|c|}
\hline \multirow{2}{*}{ Divisions } & $\begin{array}{c}\text { Table 2: Under Reporting of Road Accidents [39-49] } \\
\text { Average annual } \\
\text { road accidents } \\
(2008-2016) \text { years }\end{array}$ & $\begin{array}{c}\text { Average annual } \\
\text { road accidents } \\
(2008-2016) \text { years }\end{array}$ & $\begin{array}{c}\text { Data ascertainment } \\
(2008-2016) \text { years }\end{array}$ \\
\cline { 2 - 4 } & $\begin{array}{c}\text { Estimated by } \\
\text { Punjab Emergency } \\
\text { Services (PES) }\end{array}$ & $\begin{array}{c}\text { Reported to Police } \\
\text { Punjab } \\
\text { Development } \\
\text { Statistics (PDS) }\end{array}$ & (Reported/Estimated) *100 \\
\hline Bahawalpur & 10.38 & 0.69 & $6.64 \%$ \\
\hline DG khan & 80.92 & 0.65 & $0.80 \%$ \\
\hline Faisalabad & 21.15 & 0.41 & $1.94 \%$ \\
\hline Gujranwala & 21.04 & 0.66 & $3.13 \%$ \\
\hline Lahore & 43.37 & 1.16 & $2.68 \%$ \\
\hline Multan & 15.75 & 0.36 & $2.31 \%$ \\
\hline Rawalpindi & 8.44 & 0.84 & $9.96 \%$ \\
\hline Sahiwal & 8.80 & 0.27 & $3.08 \%$ \\
\hline Sargodha & 6.78 & 0.47 & $6.86 \%$ \\
\hline Average Annual reported accidents in whole province Punjab & $37.40 \%$ \\
\hline Average annual under-reported accidents in whole province & $62.60 \%$ \\
\hline \multicolumn{2}{|c|}{ Punjab } & & \\
\hline
\end{tabular}

strategies and future road safety plans. Study should acknowledge its limitations of using statistical reports data 2008-2016 for both road accidents and registered vehicle increase. Meanwhile, lack of availability of the data regarding vehicle type involvement in road accidents and hospital records of road accident led to exclude it from the scope of the study and acknowledged here as a limitation. Future studies should extend the current under reporting literature by considering other sources of accident data such as 
hospital records data and vehicle type involvement in road accidents.

\subsection{Suggestions}

With the aim of providing mitigation approaches to deal with motorization and under-reporting issue; a rigorous literature review of available studies was conducted. And, five mitigation approaches are suggested for the better surveillance system of road safety and planned management as shown below:

- Development of effective transportation policy with great focus on motorization and safety issue, and its enforcement at national and sub-national level [8,19, 21, 50-53].

- Consideration the potential impact of spatial variations on motorization and road accidents [7, 38, 54-57].

- $\quad$ Prioritization and allocation of the road safety and development funds by considering area severity [2, 35, 56, 57].

- Increase the coordination and collaboration of Police, Health, law and Transport department [7, $23,35,38]$.

- Introduction of real time traffic management system, and advancement in road accident data recording and management system [13,14,28,57].

In view of WHO-2030 agenda on road safety for sustainable development; Pakistan national transport policy-2017 was drafted, focusing road safety issue. In the past, same exercise was also conducted, but the results were not so impressive, because of lack of funding, monitoring issues, and political interest [19]. This time, the government needs to pay more attention to develop feasible and effective policy measures for road safety. The academia and international research groups should involve conveying technical assistance in order to limit the loss of lives from road accidents. Road safety cannot be achieved without effective predictions and preventions, which required effective management and collection of road accidents data. In the case of Punjab, the Punjab Safe Cities Authority can assist in road accident data management. Recently, Punjab Safe Cities Authority identified 2,000 locations for installing 10,000 surveillance cameras, which may help in future for road accident data-collection and monitoring at the same time [53].

\section{CONCLUSION}

The study sets three objectives to overall highlight the motorization and under reporting of road accidents. The first objective results into the drafting of motorization level trend for Punjab divisions. Like the provinces of other developing countries, Punjab showed a continuous increase in motorization, which differed significantly from one division to another division. The main reasons were highlighted as the lack of research in motorization subject and the absence of distinct transportation policy. Second objective of illustrating the spatial dominance of registered vehicles was attained through calculating the Compound Annual Growth Rate (CAGR) of registered vehicle increase combined with its spatial representation on divisional maps. This evidence of spatial variation in growth of Cars, Motorcycles, Rickshaws, Trucks, Vans and other vehicles (including Taxi, Buses, Tractors, etc.) indicated the risky areas with higher vehicular growth rate than the infrastructural development (road length). Though, indepth view of every vehicle type dominancy was discussed spatially, to portrait the brief image of motorization in Punjab, which can be used by policy makers. Third objective related to under reported road accidents highlighted the differences of average annual road accidents from police reported and emergency services data in all divisions of Punjab Pakistan. The under-reporting of road accidents may cause inefficient fund distribution for road safety and may also badly influence the predictions and preventions for safety measures. This paper folds motorization and under-reporting issues together and deliver a guiding path for policy-making agencies, in order to achieve the road safety target of WHO-2030 agenda.

\section{ACKNOWLEDGEMENT}

First two Authors are grateful to China Scholarship Council (CSC) for providing the financial support to pursue post graduate studies in China. Authors are also thankful to faculty staff of School of Transportation 
and Logistics, Dalian University of Technology for providing technical guidance in conducting this research.

\section{REFERENCES}

1. Ma H., Yang X., Shi Q., "Motorization Process and Management In Big Cities In China", IATSS Research, Vol. 31, No.2, pp. 42-47, 2007.

2. Willoughby C., "Singapore's Motorization Policies 1960-2000”, Transport Policy, Vol. 8, No.2, pp. 125-139, 2001.

3. Soehodho, S., "Motorization In Indonesia and Its Impact to Traffic Accidents", Vol. 31, No.2, pp. 27-33, 2007.

4. Han S.S., "Managing Motorization in Sustainable Transport Planning: The Singapore Experience", Journal of Transport Geography, Vol. 18, No.2, pp. 314-321, 2010.

5. Spoerri A., Egger M., von Elm E., "Mortality from Road Traffic Accidents in Switzerland: Longitudinal and Spatial Analyses", Accident Analysis and Prevention, Vol. 43, No.1, pp. 4048, 2011.

6. "World Health Organization, World report on road traffic injury prevention", http://www.who.int/violence_injury_prevention/ publications/road_traffic/world_report/en/, 2014.

7. Lateef M.U., "Spatial Patterns Monitoring of Road Traffic Injuries in Karachi Metropolis", International Journal of Injury Control and Safety Promotion, Vol. 18, No.2, pp. 97-105, 2011.

8. Kar S., Das S.C., Tiwari A., Pharveen I., "Pattern of Road Traffic Accidents in Bhubaneswar, Odisha", Clinical Epidemiology and Global Health, Vol. 4, No.3, pp. 115-119, 2016.

9. Kitamura Y., Hayashi M., Yagi E., "Traffic Problems in Southeast Asia Featuring the Case of Cambodia's Traffic Accidents Involving Motorcycles", IATSS Research, Vol. 42, No.4, pp. 163-170, 2018.

10. "World Health Organization., Global Status Report on Road Safety 2018”, https://www.who.int/

11. Valli P.P., "Road Accident Models For Large Metropolitan Cities Of India”, IATSS Research, Vol. 29, No.1, pp. 57-65, 2005.

12. Ponnaluri R. V., "Modeling Road Traffic
Fatalities in India: Smeed's Law, Time Invariance and Regional Specificity", IATSS Research, Vol. 36, No.1, pp. 75-82, 2012.

13. Ahmed A., Khan B.A., Khurshid M.B., Khan M.B., Waheed, A., "Estimating National Road Crash Fatalities Using Aggregate Data", International Journal of Injury Control and Safety Promotion, Vol. 23, No.3, pp. 249-254, 2016.

14. Ponnaluri R. V., "Road Traffic Crashes and Risk Groups in India: Analysis, Interpretations, and Prevention Strategies", IATSS Research, Vol. 35, No.2, pp. 104-110, 2012.

15. Rahman M.K., Crawford T., Schmidlin T.W., "Spatio-Temporal Analysis of Road Traffic Accident Fatality in Bangladesh Integrating Newspaper Accounts and Gridded Population Data”, Geo Journal, Vol. 83, No.4, pp. 645-661, 2018.

16. Singh S.K., "Road Traffic Accidents in India: Issues and Challenges", Transportation Research Procedia, Vol. 25, pp. 4708-4719, 2017.

17. Zafar S.N., Canner J.K., Nagarajan N., Kushner A.L., Gupta S., Tran T.M., Nagarajan N., Stewart B.T., Kamara, T.B., Kyamanywa, P., Amatya, K.S., Galukande M., Petroze R.T., Nwomeh B.C., Smith E.R., Haglund M.M., Nwomeh B., Groen R.S., Kushner A.L., "Road Traffic Injuries: Cross-Sectional Cluster Randomized Countrywide Population Data from 4 LowIncome Countries", International Journal of Surgery, Vol. 52, pp. 237-242, 2018.

18. Bhatti J.A., Salmi L.R., "Challenges in Evaluating the Decade of Action for Road Safety in Developing Countries: A Survey of Traffic Fatality Reporting Capacity in the Eastern Mediterranean Region", Traffic Injury Prevention, Vol. 13, No.4, pp. 422-426, 2012.

19. Nazir E., Nadeem F., Véronneau S., "Road Safety Challenges in Pakistan: An Overview", Journal of Transportation Security, Vol. 9, No.3-4, pp. 161174, 2016.

20. Government of Pakistan, Ministry of Planning Development and Reforms Pakistan., "National Transport Policy of Pakistan 2017', (Draft for concurrence), 2017.

21. Hyder A.A., Ghaffar A.A., Sugerman D.E., Masood T.I., Ali L., "Health and Road Transport in Pakistan", Public Health, Vol. 120, No.2, pp. 
132-141, 2006.

22. Senbil M., Zhang J., Fujiwara A., "Motorization In Asia”, IATSS Research, Vol. 31, No.1, pp. 4658, 2007.

23. Hyder A.A., "Motor Vehicle Crashes in Pakistan: The Emerging Epidemic", Injury Prevention, Vol. 6, No.3, pp. 199-202, 2000.

24. Aslam M.W., Batool Z., "Evaluation of Urban Bus Transport Failure in Gujranwala City of Pakistan", Mehran University Research Journal of Engineering and Technology, Volume 36, No.3, pp. 469-478, 2017.

25. Ahmad R., Mi H., "China-Pakistan Economic Corridor and Its Social Implication on Pakistan: How Will CPEC Boost Pakistan's Infrastructures and Overcome the Challenges?", Arts and Social Sciences Journal, Vol. 08, No.02, 2017.

26. Kayani A., Fleiter J.J., King M.J., "Underreporting of Road Crashes in Pakistan and the Role of Fate", Traffic Injury Prevention, Vol. 15, No.1, pp. 34-39, 2014.

27. The World Bank., "Lower Middle Income I Data", The World Bank Data, 2018. https://data.worldbank.org/income-level/lowermiddle-income.

28. Batool Z., Carsten O., Jopson A., "Road Safety Issues in Pakistan: A Case Study of Lahore", Transportation Planning and Technology, Vol. 35, No.1, pp. 31-48, 2012.

29. Farooq M., Asim M., Imran M., Imran S., Ahmad J., Younis M.R., "Mapping Past, Current and Future Energy Research Trend in Pakistan: A Scientometric Assessment", Scientometrics, Vol. 117, No.3, pp. 1733-1753, 2018.

30. Dereli M.A., Erdogan S., "A New Model for Determining the Traffic Accident Black Spots Using GIS-Aided Spatial Statistical Methods", Transportation Research Part A: Policy and Practice, Vol. 103, pp. 106-117, 2017.

31. Roque D., Masoumi H.E., "An Analysis of Car Ownership in Latin American Cities: A Perspective for Future Research", Periodica Polytechnica Transportation Engineering, Vol. 44, No.1, pp. 5-12, 2016.

32. Tahir N., Naseer R., Khan S.M., Macassa G., Hashmi W., Durrani M., "Road Traffic Crashes Managed by Rescue 1122 in Lahore, Pakistan", International Journal of Injury Control and Safety
Promotion, Vol. 19, No.4, pp. 347-350, 2012.

33. Periyasamy N., Lynch C.A., Dharmaratne S.D., Nugegoda D., Østbye T., "Under Reporting of Road Traffic Injuries in the District of Kandy, Sri Lanka", BMJ Open, Vol. 3, No.11, pp. 1-7, 2013.

34. Wangdi C., Gurung M.S., Duba T., Wilkinson E., Tun Z.M., Tripathy J.P., "Burden, Pattern and Causes of Road Traffic Accidents in Bhutan, 2013-2014: A Police Record Review", International Journal of Injury Control and Safety Promotion, Vol. 25, No.1, pp. 65-69, 2018.

35. Watson A., Watson B., Vallmuur K., "Estimating Under-Reporting of Road Crash Injuries to Police Using Multiple Linked Data Collections", Accident Analysis and Prevention, Vol. 83, pp. 18-25, 2015.

36. Singh P., Lakshmi P.V.M., Prinja S., Khanduja P., "Under-Reporting of Road Traffic Accidents in Traffic Police Records- a Cross Sectional Study from North India", International Journal of Community Medicine And Public Health, Vol. 5, No.2, pp. 579, 2018.

37. Qin E.S., Jennissen C.A., Wadman C.A., Denning G.M., "Using Geospatial Mapping to Determine the Impact of All-Terrain Vehicle Crashes on Both Rural and Urban Communities", Western Journal of Emergency Medicine, Vol. 18, No.5, pp. 913-922, 2017.

38. Rana I.A., Bhatti S.S., Arshad H.S.H., "Assessing the Socioeconomic and Infrastructure Development Disparity - a Case Study of City Districts of Punjab, Pakistan", International Journal of Urban Sustainable Development, Vol. 9, No.3, pp. 346-358, 2017.

39. Punjab Bureau of Statistics., Punjab Development Statistics (2008), 2008. www.bos.gop.pk

40. Pakistan Bureaue of Statistics., Pakistan Development Statistics (2009), 2009. www.pbs.gov.pk/

41. Punjab Bureau of Statistics., Punjab Development Statistics (2010), 2010. www.bos.gop.pk

42. Punjab Bureau of Statistics., Punjab Development Statistics (2011), 2011. www.bos.gop.pk

43. Punjab Bureau of Statistics., Punjab Development Statistics (2012), 2012. www.bos.gop.pk

44. Punjab Bureau of Statistics., Punjab Development Statistics (2013), 2013. www.bos.gop.pk

45. Punjab Bureau of Statistics., Punjab Development 
Statistics (2014), 2014. www.bos.gop.pk

46. Punjab Bureau of Statistics., Punjab Development Statistics (2015), 2015. www.bos.gop.pk

47. Punjab Bureau of Statistics., Punjab Development Statistics (2016), 2016. www.bos.gop.pk

48. Punjab Bureau of Statistics., Punjab Development Statistics (2017), 2017. www.bos.gop.pk

49. Punjab Emergency Service., "Rescue 1122 Statistics" 2018. www.rescue.gov.pk

50. Vilela da Silva, L. de O., Braga M.G. de C., "Violent Events on the Road: Risk Perception of Traffic-Related and Non Traffic-Related Situations", Accident Analysis and Prevention, Vol. 114, No.August 2016, pp. 55-61, 2018.

51. Pucher J., Peng Z.R., Mittal N., Zhu Y., Korattyswaroopam, N., "Urban Transport Trends and Policies in China and India: Impacts of Rapid Economic Growth", Transport Reviews, Vol. 27, No.4, pp. 379-410, 2007.

52. Talpur M.A.H., Ali T.H., Chandio I.A., Shaikh F.A., "Transportation Planning Studies for SocioEconomic Development of Depressed SubRegions: A Review", Mehran University Research Journal of Engineering and Technology, Vol. 37, No.3, pp. 603-614, 2018.
53. Bonnet E., Nikiéma A., Traoré Z., Sidbega S., Ridde V., "Technological Solutions for an Effective Health Surveillance System for Road Traffic Crashes in Burkina Faso", Global Health Action, Vol. 10, No.1, 2017.

54. Yalcin G., "Non-Spatial Analysis for the Road Traffic Accidents", Procedia - Social and Behavioral Sciences, Vol. 92, pp. 1033-1038, 2013.

55. Zubair S., Ghazal L., "Evaluating the Road Safety Design through High Resolution Satellite Image: A Case Study of Karachi Metropolitan", MATEC Web of Conferences, Vol. 81, 2016.

56. Naji, J.A., Djebarni, R., "Shortcomings in Road Accident Data in Developing Countries, Identification and Correction: A Case Study" , IATSS Research, Vol. 24, No.2, pp. 66-74, 2000.

57. Adnan, S., Shah, R., Khattak, A., "Road Traffic Accident Analysis of Motorways in Pakistan", International Journal of Engineering Research \& Technology, Vol. 2, No.11, pp. 3340-3354, 2013. 